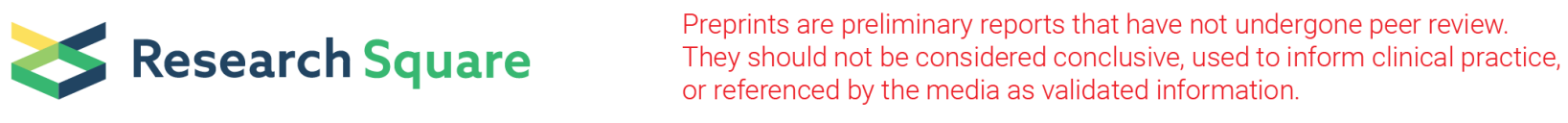

\title{
Listening to families with a person with neurodegenerative disease talk about their quality of life: integrating quantitative and qualitative approaches
}

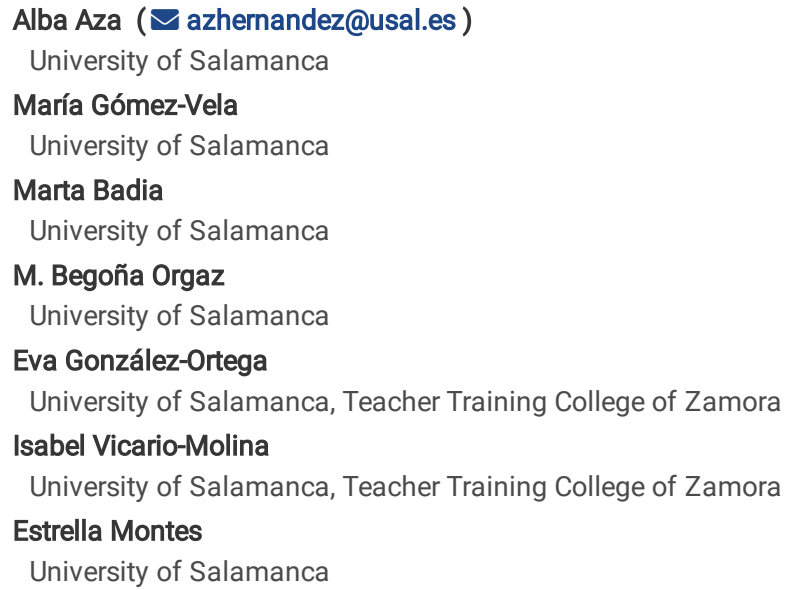




\section{Abstract}

Background: The diagnosis of a neurodegenerative disease (ND) produces profound changes in the quality of life of the affected families. Despite the vital importance of these processes, the scientific literature has addressed this topic almost exclusively relating to the main caregiver or using limited approaches. Thus, the main objective of this research is to achieve a deeper understanding of the quality of family life of people with a neurodegenerative disease, following a mixed-method approach that combines quantitative and qualitative methodology.

Methods: The quantitative instrument was the Spanish version of the Family Quality of Life Survey - Neurodegenerative Disease (FQOLS-ND), which was completed by 300 participating families. The qualitative methodology was used in two focus groups with family caregivers, with a total of 21 participants.

Results: On the one hand, confirmation of the dimensional structure of the scale in the focus groups was obtained and, on the other hand, the results of family quality of life in attainment and satisfaction were shown to be high for Family Relations and Careers and Planning for Careers and low for Support from Services and Leisure and Recreation.

Conclusions: The results of this study, through the combination of quantitative and qualitative information, helps to identify key issues to optimize services that respond to the priority needs of families.

\section{Background}

Neurodegenerative diseases (ND) have a significant impact on the lives of people who experience them, producing a progressive deterioration in cognitive, physical, and social functioning. This leads to a growing loss of independence and an increase in care and support needs (Page et al., 2017). According to the World Health Organization (WHO, 2019), dementias are responsible for the greatest burden of ND and affect around 50 million people worldwide. In Spain, there are more than one million people affected by different NDs. Alzheimer's disease and other neurodegenerative conditions, such as Parkinson's disease, multiple sclerosis, neuromuscular diseases, and amyotrophic lateral sclerosis, are the most prevalent, affecting $5.4 \%$ to $14.9 \%$ of people over 65 years (Garcés, 2016). In a recent epidemiological study (Alonso-Sardón \& NEUROQUALYFAM group, 2021) carried out in the rural cross-border area of Spain-Portugal, the prevalence of Alzheimer's disease and other dementias was estimated at $4.5 \%$, Parkinson's disease at $2.7 \%$, and multiple sclerosis at $0.03 \%$.

The family is a major determinant of positive outcomes in people with ND. It provides emotional and practical support, social care, and assistance in the basic and instrumental activities of daily life (Manthorpe \& Bowling, 2016). Living with a person with ND is a huge challenge that can lead to negative consequences, among which are anxiety and depression, stress, burnout, and social isolation (Madruga et al., 2020). However, the caregiving role can also have positive effects such as greater closeness to the affected person, reciprocity, and spiritual growth (Vellone et al., 2012). When we refer to family, we adopt the broad sense of the word, meaning "people who are closely involved in the daily affairs of the home and support each other on a regular basis, whether they are related by blood, marriage, or a close personal relationship" (Park et al., 2003; Rilotta et al., 2012) and including the person with ND. In the last few years, the study of Family Quality of Life (FQoL) has increased, understood as a "dynamic sense of family well-being, collectively and subjectively defined and informed by its members, in which individual and family-level needs interact" (Zuna et al., 2010, p. 246). It is a perspective that considers the family as an interconnected system, such that ND affects not only the person who suffers from it and their family members, but also the interaction that occurs between them (Esandi \& Canga, 2016; Riedel et al., 2013).

Like individual quality of life (QoL), FQoL is a multidimensional construct that includes both objective and subjective indicators, which has been primarily and effectively studied in the evaluation of the strengths and challenges of family caregivers of individuals with disabilities and chronic health conditions (Samuel \& DiZazzo-Miller, 2019). According to the FQoL theory, individual member concepts (i.e., demographics, characteristics, and beliefs) and family-unit concepts (i.e., dynamics and characteristics) are direct predictors of FQoL and they interact with individual and family-level supports, services, and practices (Ducharme \& Geldmacher, 2011).

Given the importance of the role of the family caregiver for people with ND (DiZazzo-Miller et al., 2013), the family needs to maintain good levels of FQoL. Hence, the views of families are a starting point for the design of support plans (Balcells-Balcells et al., 2019) and the improvement of professional attention, services, policies, and state, regional, and local programs.

To monitor this process effectively, it is necessary to have psychometrically robust measures, and, as far as possible, specific for this population (Page et al., 2017). One of the most widely used scales is the Family Quality of Life Survey-2006 (FQOLS; Brown et al. 2006), which considers nine life domains in terms of importance, opportunities, attainment, initiative, stability, and satisfaction. This scale was initially constructed for families caring for a family member with an intellectual disability but has been adapted and validated for other populations, such as ND (Author et al., 2021; Rose et al., 2020; Samuel \& DiZazzo, 2019).

However, FQoL also has subjective components, so it would be unwise to base its evaluation exclusively on quantitative data. Qualitative assessments are important because beliefs and attitudes are relevant for understanding caregivers' feelings and behavior (Murray et al., 1999). In this regard, focus groups elicit perspectives of the targeted population on issues of concern through structured and facilitated discussion (Teitelman et al., 2011). They are particularly useful in the analysis of specific factors in the life of the participants, such as FQoL (Den Oudstene et al., 2011; Veronese et al., 2015). Some studies using focus groups (e.g., Ducharme \& Geldmacher, 2011) indicate that disability-related support, medical care, and physical and cognitive well-being were by far the most cited needs in this population.

The literature has focused on the QoL of family caregivers from the main caregiver's point of view, paying less attention to the QoL of the whole family unit (Martínez-Martín et al., 2012; Oliveira et al., 2015). It has also used either quantitative or qualitative models, seldom considering the positive contributions of the combination of both models through a mixed-methods approach (Longo-Araújo \& Moreno-Valdés, 2007; Schmidt et al., 2016; Steel et al., 2011). 
Therefore, the objective is to study FQoL in families with one or more members with ND by using a mixed-methods approach, i.e., contrasting the application of a specific quantitative instrument for this population with the qualitative assessments made by the families using the focus group methodology.

Specifically, we intend to (1) confirm whether the FQoL domains, as evaluated with the Family Quality of Life Survey-Neurodegenerative Disease (FQOLS-ND; Author et al., 2021), can be replicated qualitatively; and (2) obtain a deeper understanding of the attainment and satisfaction dimensions of the FQOLS-ND by comparing the quantitative and qualitative data.

\section{Methods Participants}

Participants in the quantitative assessment and those who participated in the focus groups were not the same.

Participants for the quantitative part were recruited by the Regional Health Management (RHM) of Castille and Leon (Spain), between October 2019 and July 2020. Family members of patients with ND were invited to participate if they met the following inclusion criteria: (1) contribute to the daily care of the person with ND but not necessarily as the primary caregiver; (2) 18 years of age or older; (3) live in the cross-border area of Spain-Portugal. Families whose member with an ND lived in residential accommodation were excluded. The RHM selected 890 families from the population ( $N=987$; Dementia: $58.7 \%$, Parkinson: $37.7 \%$, Multiple Sclerosis: $3.6 \%$ ). A total of 380 family members signed the informed consent to participate, but 74 of them were not accessible $(n=35)$, available $(n=2)$, or willing to collaborate $(n=37)$.

Participants for the qualitative part of the study were recruited between November 2019 and January 2020, with the support of the following associations: Asociación de Familiares de Enfermos de Alzheimer (AFA Salamanca), Asociación de Familiares de Enfermos de Alzheimer de Béjar y Comarca (AFABECO), Asociación Parkinson de Salamanca and Asociación Salmantina de Esclerosis Múltiple (ASDEM). Family members of patients with ND were invited to participate if they met the same inclusion-exclusion criteria as the quantitative study. All those interested in participating received information (verbal and written) on the objectives of the study and the research technique to be used. None of the participants had comprehension or oral expression difficulties in Spanish. Finally, 21 people signed the informed consent form and participated in two focus groups (10 in the first and 11 in the second).

\section{Instruments}

The study used both quantitative and qualitative methods. The rationale of this particular mixed-methods design is that quantitative instruments provide empirical information on the QoL of extensive groups of family caregivers of persons with ND and help to plan, implement, and measure the effectiveness of family-centered interventions (Samuel et al., 2012), whereas qualitative methods allow researchers to talk directly with caregivers to learn about their experiences (van Manen, 1990), perceptions, and the supports needed. Concurrently, combining quantitative and qualitative analyses allow us to corroborate the information gathered from both approaches and to achieve a deeper understanding of FQoL (Steel et al., 2011).

The quantitative instrument was the Spanish version of Family Quality of Life Survey-Neurodegenerative Disease -FQOL-ND (Author et al., 2021), translated, adapted, and validated from the FQOLS-Dementia (DiZazzo-Miller et al., 2013). Part A includes questions about the family and the person with ND, which range from general socio-demographic issues to more specific ones, such as the supports needed by the family member with ND or the degree of independence in daily life activities. Part B contains nine life domains (i.e., Family Health, Financial Well-being, Family Relationships, Support from Others, Support from Services, Influence of Values, Careers, Leisure and Recreation, and Community Interaction) to examine how the family perceives its FQoL. In the Spanish version, only the attainment and satisfaction dimensions for each of the domains have been considered and validated, because they are the two main outcome measures with the best psychometric results (Author et al., 2021; Brown, 2006, 2015; Samuel \& DiZazzo, 2019; Schmidt et al., 2016). These dimension items collect quantitative data on a 5-point Likert scale, with higher scores indicating higher levels of attainment or satisfaction in the specific domain. The final section consists of two close-ended questions about global impressions of FQoL. The internal consistency was strong for all domain subscales (from $a=.80$ to .91) and excellent for the total FQOL-ND scale $(a=.85)$ and the Global FQOL-ND scale ( $a=.87)($ Author et al., 2021).

Using a qualitative perspective, two separate focus groups were conducted, and data were collected using guiding questions to identify core QoL dimensions for families of persons with ND, to obtain information on how ND affects FQoL, and to check and/or modify the nine domains of the FQOL-ND ( Appendix 1).

A protocol was designed to ensure the systematic development of two focus groups, considering the quality indicators of DiZazzo et al. (2013): greeting participants, a brief introduction to the goals of the research, informed consent, basic rules about the group's functioning, and main topics (i.e., Family QoL and the nine domains).

\section{Procedure}

In the quantitative evaluation, the questionnaires were administered by telephone in about 30 minutes by trained and experienced interviewers to comply with the social distancing restrictions of the COVID-19 pandemic. Verbal and written informed consent was obtained after informing participants about the aim of the study and their right to drop out at any time.

In the qualitative study, the first focus group took place at the Association of Family Members of People with Alzheimer's in Béjar, a rural zone in Salamanca, and the second group at the Parkinson's Association in Salamanca (Spain), both led by a researcher with training and experience. With the participants' agreement, a voice recorder was used, and a co-researcher was present, who took notes to ensure data collection consistency across groups and to minimize data loss. The focus groups were conducted using the guiding questions (Appendix 1) in about 2.5 hours. 
The study was approved by the Bioethics Committee of the XXX (Protocol No. 2019/238). All procedures comply with the principles of the 1964 Declaration of Helsinki and its amendments. Verbal and written informed consent was obtained from all participants prior to data collection.

\section{Data Analysis}

Quantitative data were analyzed using SPSS 26. The statistical significance was set at $p \leq .05$. Descriptive data were displayed as the mean, SD, and range, or absolute and relative frequencies. Next, repeated-measures ANOVAs were used to compare the nine domains, the two dimensions, and the interaction between domains and dimensions.

In the qualitative analysis, the transcribed texts of the focus groups were analyzed by means of Atlas.ti 7. A deductive method was used, that is, a codebook based on the literature was created to guide the process of encoding the information, keeping in mind the comprehensiveness of the data and the objectives of the study (i.e., content analysis). The first step in the analysis consisted of identifying text segments suitable for coding. These fragments were relatively large to allow embedding them in their logical context. A tree structure was gradually refined and attuned to clarify the definitions of categories and subcategories.

\section{Results}

\section{Sample characteristics}

The final sample for the quantitative part of the study consisted of 300 participants (mean age $=62.4, S D=13.34$ ). The majority were females, married/with a partner, not working, with low income - up to 1000 EUR per month- and had primary or secondary school qualifications. Most of them were the spouse/partner or son/daughter of the person with ND, they had the role of primary caregiver and lived in the same household. Most of them lived in rural areas of up to 500 or 500-10000 people (Table 1).

\section{[TABLE 1]}

As for the characteristics of the care recipients, their mean age was 79.3 years $(S D=11.7)$, and most were females. The majority suffered from dementia with some level of dependence, generally high or moderate (Table 2).

\section{[TABLE 2]}

For the qualitative part of the study, two focus groups were formed, one composed of 10 and the other of 11 participants. The caregiver's age ranged between 40 and 79 years. The majority were females, spouse/partner of the care-recipient, and they had the role of primary caregiver (Table 3).

[TABLE 3]

\section{Confirmation of FQOL-ND structure}

The structure of the Spanish version of the FQOL-ND (Author et al., 2021) reproduces the original scale (DiZazzo-Miller et al., 2013).

In this study, all the domains included in the FQOL-ND scale were mentioned in both focus groups, thus confirming their structure. Appendix 2 shows in detail the categories and codes analyzed in each dimension and how many times they were mentioned in each focus group. questions could not be framed within any of the domains of the scale, for example, aspects related to gender ("Society itself imposes excessive psychological dependence, especially for women. Therefore, you feel guilty if you do not do certain things, so you shame yourself into doing them") and love and affection as an explanation of care ("We have 'endured' it, but I do not want to say it in quotes, because I do it with love').

The analyses of the information obtained in the focus groups revealed that Support from Services (32.7\%) and Family Health (31.5\%) were the most frequently mentioned topics, and the dimensions with the lowest number of mentions were Support from Others (1.4\%) and Careers and Planning for Careers (0.8\%).

\section{Domains and dimension's analysis}

The mean scores, medians, and standard deviations for attainment and satisfaction in the nine domains are shown in Table 4, as well as the global and general scores. Table 5 includes the response percentages for each of the Likert-type options.

[TABLE 4]

[TABLE 5]

ANOVA revealed significant differences between the domains, $F_{(8,2392)}=96.77, p<.001, \eta_{P}^{2}=.25$. The significantly higher domains were Family Relationships and Careers and Planning for Careers, whereas the significantly lower ones were Support from Services and Leisure and Recreation $(p<.001)$. Results indicated a significant difference between the dimensions, $F_{(1,299)}=118.96, p<.001, \eta_{P}^{2}=.29$. The mean level of satisfaction was significantly higher than that of attainment. The interaction Domains $X$ Dimensions was significant, $F_{(8,2392)}=32.69, p<.001, \eta_{P}^{2}=.10$, and the post hoc tests revealed that the mean 
level of satisfaction was higher than that of attainment in eight of the nine domains, although these differences were only significant $(p \leq .001)$ in Support from Others, Support from Services, Influence of Values, Leisure and Recreation, and Community Interaction.

The relatively high mean scores across dimensions and domains suggest that the participating families generally considered their FQoL as moderate to high. The standard deviation showed considerable variation in individual scores. On another hand, in the focus groups, the QoL of the primary caregiver was generally adversely affected after the onset of ND, as also occurred in the rest of the family. However, resilient skills focused on disease acceptance also emerged:

For me, quality of life is normalization. We cannot return to the normality that we had before because they [the member with ND] present loss of balance, dizziness, they fall asleep, their vocalization fails a lot but I think that, concerning quality of life, we must focus on acceptance. The better we accept our situation, the better we can deal with it, so we do not get exhausted or wear them [the member with ND] out.

And we take it with humor. Let's see, I think it's very dramatic, but we have to laugh. I find laughing so basic.

Then the more extreme scores of these domains were analyzed one by one with mixed methods.

\section{Family relationships}

Concerning family relationships, there were high levels of achievement $(M=4.41, S D=0.72)$ and satisfaction $(M=4.35, S D=0.80)$, in most cases $(50.7 \%)$ reported as "very satisfactory" or "satisfactory" (37.3\%). At the qualitative level, participants mentioned the unavailability of other family members (e.g., siblings of the caregiver or the person with ND) to help with the ongoing tasks. This was mainly due to work or geographical remoteness and hence, the responsibility fell on the main caregiver. However, the existence of timely supports or supports that do not require the physical presence of other family members was also mentioned, which contributed to FQoL in family relationships:

In our case, my sister lives farther away so she cannot come every day to take care of her [the family member with ND]. But we go together to the meetings of the care association and support my mother.

There was a duality in some cases where the presence of the ND constituted a family crisis ("Well, in your case, she [the patient] is your wife, but in my case, it is my brother. I have other brothers. One brother understands it [the situation], but the other does not and says: 'Well, just to leave it.' How can just leave the situation? How am I going to leave it if he [the patient] is my brother?") but in other cases, ND contributed to the family's union ("The same as I tell you that it has united the family a lot, I also tell you that our friends have disappeared").

\section{Careers and planning for careers}

Less than $20 \%$ of families showed some level of dissatisfaction with their job. However, there was a high percentage of family members who were retired (64.7\% of our sample was not working, was retired, or unemployed). In fact, in the case of actively working people, ND had a significantly negative effect both on the person with ND and on the other family members, either because they had to give up their jobs or their work obligations were incompatible with the care tasks at the long term:

Of course, it [caring for my family member] is already starting to affect my job.

\section{Support from services}

The satisfaction, and especially attainment, of Support from Services was very low $(M=3.11, S D=1.11 ; M=2.83, S D=1.02$, respectively). Concerning the health care of people with ND and their families, there were some complaints about the treatment by the primary care teams and specialized health care services. Moreover, access to a specialized professional or receiving their continuous attention was considered especially problematic. There was also a lack of information about the diagnosis and progression of ND and the needs of the patient:

Another thing I am concerned about is that family caregivers, in this case, husbands or wives, do not receive any help, either psychological or motor. How should you move your husband? You don't know anything about posture, you are just messing about. How should you treat him?

However, cases of high satisfaction with specialized care professionals were also reported, highlighting the importance of feeling heard and cared for as a priority.

Among the social care services, the psychological and technical support, both for the family and the person with ND, and the presence of resources such as day centers/associations were highlighted as a need. On another hand, residential centers were considered as an option when the disease was more advanced or when the family could not take care of the person with ND. In addition, significant differences were found in the services associated with the person's diagnosis:

I consider Parkinson's disease as the big loser. The big loser or the big forgotten. When you talk about Parkinson's, well, it means that the person stays at home and gets the tremors... I mean, that is the least... But when you mention Alzheimer's, there are residences for Alzheimer's, there are aids... 
Regarding the barriers encountered in access to services, family members highlighted the scarcity of resources (in general and particularly in the rural environment), the lack of public subsidies, the high cost of private resources, the short duration or intensity of care, with patient overloads resulting in lowerquality care or long waiting times to access the resources they needed:

I think the medication does not control it [the ND] very well. I also detect patients who should have a much more timely follow-up, who do not have it. In fact, he [the person with ND] had problems with medication... I asked for an earlier appointment but nobody listened to me.

Therefore, they proposed the creation of more resources in the rural environment and more associations of caregivers, better access to specialized professionals, more information about the procedures to access resources and grants, and a greater number and intensity of activities to be carried out with the person with ND.

According to participants, the availability of resources would improve FQoL and would not only be a way to achieve respite in the task of care but also an opportunity for the family to establish new social ties:

... where we can meet, just like we are doing here. It is going to take a while and it looks like your problem has already improved a little bit. At least you see you are not alone.

\section{Leisure and Recreation}

The domain of Leisure and Recreation was scored low both in attainment $(M=3.25, S D=0.98)$ and satisfaction $(M=3.43, S D=0.95)$. In fact, the relatives mentioned that, ever since the family member had the ND, their leisure had been reduced, but they maintained some activities both at the family level and with people outside the family:

What we are seeing is dependence, not the sick person's dependence but the families'. The families become so totally absorbed, and their dedication is so exclusive that they give up what they used to do, their friendships, their outings, their cultural activities, their leisure time.

My eldest son says Mom, I will give you 4 hours on Tuesday for you to go to the hairdresser or out with a friend...

Although the care of the person with ND was perceived as highly demanding in terms of time, the good disposition of the other members of the family provided some respite for the main caregiver who devoted more daily time to the person with ND.

\section{Discussion}

This mixed-methods study attempted to explore how various domains and dimensions of FQOL are affected when the family has an individual with ND. The findings both from quantitative and qualitative data converge in supporting the approach of nine dimensions, showing that the lives of family members are affected by their caregiving role.

The participating families considered their QoL to be moderate to high. However, considerable inter-family variability was found, highlighting the importance of the FQoL approach, which is characterized by interventions that meet the specific needs of each family (Ducharme \& Geldmacher, 2011; Isaacs et al., 2007; Summers et al., 2005). This perspective considers the family as possessing strengths and focuses the intervention on empowering and promoting competence and other positive aspects of family functioning (Dunst \& Trivette, 2009).

Despite the impact of caring for a person with ND in important aspects of family life such as health, leisure time, work and plans, and expectations, the participants rated their FQoL as quite satisfactory, a finding also observed in studies with caregivers of individuals with developmental disabilities and dementia (Pothiban et al., 2020; Samuel et al., 2016; Samuel \& DiZazzo-Miller, 2019). Also, in terms of attainment and satisfaction, caring families reported high rates in Family and Careers but low rates in Leisure and Recreation and Support from Services. These results are consistent with other studies suggesting the positive effect of high-quality family relationships and the limited effect of caring for the person with ND on Careers and Planning for careers (Pothiban et al., 2020; Samuel \& DiZazzo-Miller, 2019). There were also difficulties in accessing adequate professional services and enjoying leisure activities (Alwin et al., 2010; Bauer et al., 2019; DiZazzo-Miller et al., 2013).

FQoL domains were explored in greater depth using focus groups. Regarding health aspects, the families reported that the behavioral problems, memory disorders, and limitations in communication presented by the person with ND affected family well-being. Consistently, several studies have shown that behavioral and cognitive alterations produce significant levels of discomfort in the caregivers (Cheng, 2017; Ducharme \& Geldmacher, 2011; Farina et al., 2017; Feast et al., 2016). Likewise, the main caregivers complained about their psychological well-being, associated with overload, inability to disconnect, feelings of loneliness and discomfort linked to the suffering of their family member, factors widely confirmed by the previous literature (Cooper et al., 2007; Cuijpers, 2005; Farina et al., 2017; Nolan et al., 2002). At the same time, they underlined that the care required by the person with ND also affected the psychological wellbeing of other family members (Celdrán et al., 2012).

Caring for a person with ND implies a detriment to family finances. The families stated that they did not have sufficient financial support to adequately cover the costs of caring for the person with ND (e.g., conditioning the home to the needs of the person with ND). In Spain, the family is the great provider of support 
resources, and this implies no cost to the public health and social services system but a very high cost for the families (Garcés, 2016). In addition, the family careers of people living in rural areas are at a greater disadvantage, generally receiving lower incomes (Ehrlich et al., 2017).

An important aspect that contributes to FQoL is the support families receive from others. The families reported that they did not receive emotional and practical support from their extended family, friends, or neighbors. This situation produces feelings of loneliness and social isolation. These results confirm previous studies that highlight the negative consequences of the lack of informal supports for the family (Daley et al., 2019; Farina et al., 2017; Mateo et al., 2000; Pothiban et al., 2020; Samuel \& DiZazzo-Miller, 2019).

Regarding how the person with ND has conditioned family relationships, the participants stated that they were satisfied, suggesting that families can generally make the emotional adjustment to understand and accept the disease and its care (Esandi \& Canga, 2016). In our study, the responsibility for the care of the person with ND lay mostly with the main caregiver due to the work duties or the distant geographical location of the other members of the family. However, this does not prevent their relationships from being supportive, respectful, and of mutual trust. In fact, Losada-Baltar et al. (2017) concluded that family cohesion, the family's ability to communicate effectively, express emotions, and adapt to changes are essential for good family functioning.

In general, the families reported that they were dissatisfied with the professional support received, showing that the services provided are insufficient and poorly organized. In Spain, attention to dependency in the public system of social services, especially the services that support inclusion in the community and the respite of family members, is very limited (Garcés et al., 2010). This shows that the care for the person with ND falls on the family, especially, the women. Similarly, the participants expressed their difficulties in accessing social and health services appropriate to the needs of the patient and the family. For example, they highlighted the lack of resources in rural areas, the lack of information about the disease, the long waiting times to access economic benefits linked to dependency, or the low frequency and coverage of home-help. These barriers have also been identified in several studies conducted with caring families living in rural areas (Bauer et al., 2019; Chow et al., 2019; Morgan et al., 2019). However, the families in this study highlighted the relevant role of the third sector in supporting services, both for the person with ND and the family. Thus, they acknowledged the role of associations of relatives in the provision of services that the public sector cannot cover (Azúa Berra, 2017; Corral-Lagea et al., 2019).

This full dedication to caring also implies fewer opportunities for leisure and recreation (Alwin et al., 2010; Daley et al., 2019; Farina et al., 2017; Samuel \& DiZazzo-Miller, 2019). However, some comments indicated that family members offer practical and emotional support so that the main caregivers can have their own recreational spaces. Several studies have shown the positive effect of leisure activities on carers' emotional well-being, particularly social activities, and participation in self-help groups (Chien et al., 2011; Chiu et al., 2020; Schüz et al., 2015).

In the focus groups, comments were made about the lack of information about ND in people of the community, the difficulties concerning how a person with ND should be treated, as well as the presence of compassionate or negative attitudes. This is in line with the work of Losada et al. (2017), who pointed out that part of society's lack of information about ND can cause behaviors of rejection, avoidance, or ignorance about how to act in certain situations. However, our participants acknowledged the importance of the support provided by the associative movement to face these adversities. Participation in a self-help group improves FQOL outcomes, buffers the impact of the burden of care, offers social support, gives opportunities to share experiences, and stimulates social relationships (Chien et al., 2011; Mateo Rodríguez et al., 2000; Navarro-Abal et al., 2019; Schüz et al., 2015).

This study has numerous strong points associated with the complementary use of quantitative and qualitative information in the study of the FQoL of patients with ND. However, it is not without limitations. Firstly, one of the focus groups included families that lived in Salamanca rather than in rural areas and, given the statistically significant differences found between the two groups in the support of the services, more focus groups are needed to expand the information and facilitate the comparison. Secondly, the families that completed the FQOL-ND scale were not the same as those that participated in the focus groups, although the sociodemographic characteristics were the same. In future research, it would be interesting to include more focus groups to study the influence of certain factors on FQoL levels.

\section{Conclusions}

In conclusion, this mixed-methods study provides important information about how a person with ND affects families, what these families need, and how to optimize the supports provided. Thus, we found areas, such as family relationships, that were positively affected compared to others rated more negatively, such as the professional services received or leisure activities. The quantitative study provides reference values of the different quality of life domains, and the focus groups have contributed many details that numbers cannot provide.

\section{Abbreviations}

ND: Neurodegenerative diseases; FQoL: Family Quality of Life; QoL: Quality of Life; RHM: Regional Management of Health.

\section{Declarations}

\section{Ethical approval and consent to participate}

The study was approved by the Bioethics committee of University of Salamanca (Protocol No. 2019/238). All procedures comply with the principles of the 1964 Declaration of Helsinki and its amendments. Verbal consent was obtained from all participants prior to data collection.

\section{Consent for publication}


Not aplicable

\section{Avaliability of data and materials}

Data sharing is available upon reasonable request. Kindly contact the corresponding autor.

\section{Competing interests}

The authors declare that they have no competing interest.

\section{Funding}

This study was funde by the Project "NEUROQUALYFAM, Neurodegenerative Diseases and Familay Quality of Life", funded by the Fondo Europeo de Desarrollo Regional (FEDER) through the program INTERREG V-A España - Portugal (POCTEP) 2014 - 2020.

\section{Authors's contributions}

AA, MGV, and MB participated in conception, design and discussion section of the study. BO did statistical analyses and manuscript drafting. EGO did introduction and method of the manuscripts. IVM contributed to the data acquisition. EM conducted the focus groups. All authors participated in revising the manuscript. All authors redad and approved the final manuscript.

\section{Acknowledgements}

The authors would like to thank the families of people with NDs and the health and social services professionals who collaborated in the study.

\section{References}

1. Alonso Sardón, M. \& NEUROQUALYFAM Group (2021). NEUROQUALYFAM Project: Epidemiological report of the neurodegenerative diseases in the rural cross-border area of the province of Salamanca. Available at: https://gredos.usal.es/bitstream/handle/10366/145478/NEUROQUALYFAM_Informe_Epidemiologico.pdf?sequence1\&isAllowed=y

2. Alwin, J., Oberg, B., \& Krevers, B. (2010). Support/services among family caregivers of persons with dementia-perceived importance and services received. International Journal of Geriatric Psychiatry, 25(3), 240-248. doi:10.1002/gps.2328

3. Azúa Berra, P. (2017). El papel de asociaciones y fundaciones como agentes que contribuyen al bienestar social. Documentación Social, $186,81-97$.

4. Author et al. (2021) [details removed for peer review]

5. Balcells-Balcells, A., Giné, C., Guárdia-Olmos, J., Summers, J. A., \& Mas, J. M. (2019). Impact of supports and partnership on family quality of life. Research in Developmental Disabilities, 85, 50-60. doi:10.1016/j.ridd.2018.10.006

6. Bauer, M., Fetherstonhaugh, D., Blackberry, I., Farmer, J., \& Wilding, C. (2019). Identifying support needs to improve rural dementia services for people with dementia and their carers: A consultation study in Victoria, Australia. The Australian Journal of Rural Health, 27(1), 22-27. doi: 10.1111/ajr.12444

7. Brown, I., Brown, R. I., Baum, N. T., Isaacs, B. J., Myerscough, T., Neikrug, S., Roth, D., Shearer, J., \& Wang, M. (2006). Family Quality of Life Survey (general version). Surrey Place Centre.

8. Brown, I. (2015). Quality of life: Advances in individual and family quality of life for persons with neurodevelopmental disorders. Keynote address, 10th International Congress, European Association for Mental Health in Intellectual Disability, Integrating different approaches in the neurodevelopmental perspective. September 9- 11. Retrieved from

https://www.researchgate.net/publication/285055792_Quality_of_Life_Advances_in_Individual_and_Family_Quality_of_Life_for_Persons_with_Neurodevel

9. Celdrán, M., Villar, F., \& Triadó, C. (2012). When grandparents have dementia: Effects on their grandchildren's family relationships. Journal of Family Issues, 33(9), 1218-1239. doi:10.1177/0192513X12443051

10. Cheng, S.-T. (2017). Dementia caregiver burden: A research update and critical analysis. Current Psychiatry Reports, 19(9), 64-64. doi:10.1007/s11920017-0818-2

11. Chien, L. Y., Chu, H., Guo, J. L., Liao, Y. M., Chang, L. I., Chen, C. H., \& Chou, K. R. (2011). Caregiver support groups in patients with dementia: A metaanalysis. International Journal of Geriatric Psychiatry, 26(10), 1089-1098. doi:10.1002/gps.2660

12. Chiu, Y.-C., Liao, H.-C., Li, C.-L., Lin, C.-H., Hsu, J.-L., Lin, C.-Y., \& Hsu, W.-C. (2020). The mediating effects of leisure engagement on relationships between caregiving stress and subjective well-being among family caregivers of persons with cognitive impairment: A cross-sectional study. Geriatric Nursing, 41(2), 124-131. doi:10.1016/j.gerinurse.2019.08.017

13. Chow, A. F., Morgan, D., Bayly, M., Kosteniuk, J., \& Elliot, V. (2019). Collaborative approaches to team-based primary health care for individuals with dementia in rural/remote settings. Canadian Journal on Aging, 38(3), 367-383. doi:10.1017/S0714980818000727

14. Cooper, C., Balamurali, T. B. S., \& Livingston, G. (2007). A systematic review of the prevalence and covariates of anxiety in caregivers of people with dementia. International Psychogeriatrics, 19(2), 175-195. doi:10.1017/S1041610206004297 
15. Corral-Lagea, J., Maguregui-Urionabarrenechea, L., \& Maguregui-Urionabarrenechea, C. (2019). An empirical investigation of the Third Sector in Spain: Towards a unified reconceptualization. Revista de Contabilidad, 22(2), 145-155. doi:10.6018/rcsar.376151

16. Cuijpers, P. (2005). Depressive disorders in caregivers of dementia patients: A systematic review. Aging \& Mental Health, 9(4), 325-330. doi:10.1080/13607860500090078

17. Daley, S., Murray, J., Farina, N., Page, T. E., Brown, A., Basset, T., Livingston, G., Bowling, A., Knapp, M., \& Banerjee, S. (2019). Understanding the quality of life of family carers of people with dementia: Development of a new conceptual framework. International Journal of Geriatric Psychiatry, 34(1), 79-86. doi:10.1002/gps.4990

18. Den Oudsten, B.L., Lucas-Carrasco, R., Green, A.M., \& THE WHOQOL-DIS GROUP (2011). Perceptions of persons with Parkinson's disease, family, and professionals on quality of life: An international focus group study. Disability and Rehabilitation, 33(25-26), 2490-2508. doi: 10.3109/09638288.2011.575527

19. DiZazzo-Miller, R., Pociask, F. D. \& Samuel, P. S. (2013). Understanding resource needs of persons with Dementia and their caregivers. Michigan Family Review, 17(1), 1-20. doi: 10.3998/mfr.4919087.0017.102

20. Ducharme, J. K., \& Geldmacher, D. S. (2011). Family quality of life in dementia: A qualitative approach to family-identified care priorities. Quality of Life Research: An International Journal of Quality of Life Aspects of Treatment, Care And Rehabilitation, 20(8), 1331-1335. doi:10.1007/s11136-011-9852-4

21. Dunst, C. J., \& Trivette, C. M. (2009). Capacity-building family-systems intervention practices. Journal of Family Social Work, 12(2), 119-143.

22. Ehrlich, K., Emami, A., \& Heikkilä, K. (2017). The relationship between geographical and social space and approaches to care among rural and urban caregivers caring for a family member with dementia: A qualitative study. International Journal of Qualitative Studies on Health and Well-being, 12(1). doi:10.1080/17482631.2016.1275107

23. Esandi, N., \& Canga, A. (2016). Family-centered care: A model for approaching dementia care in the community. Atención Primaria, 48(4), 265-269. doi:10.1016/j.aprim.2015.11.006

24. Farina, N., Page, T. E., Daley, S., Brown, A., Bowling, A., Basset, T., Livingston, G., Knapp, M., Murray, J., \& Banerjee, S. (2017). Factors associated with the quality of life of family carers of people with dementia: A systematic review. Alzheimer's \& Dementia: the Journal of the Alzheimer's Association, 13(5), 572-581. doi:10.1016/j.jalz.2016.12.010

25. Feast, A., Moniz-Cook, E., Stoner, C., Charlesworth, G., \& Orrell, M. (2016). A systematic review of the relationship between behavioral and psychological symptoms (BPSD) and caregiver well-being. International Psychogeriatrics, 28(11), 1761-1774. doi:10.1017/S1041610216000922

26. Garcés, J., Carretero, S., Ródenas, F., \& Vivancos, M. (2010). The care of the informal caregiver's burden by the Spanish public system of social welfare: A review. Archives of Gerontology and Geriatrics, 50(3), 250-253. doi:10.1016/j.archger.2009.04.011

27. Garcés, M. (2016). Estudio sobre las enfermedades neurodegenerativas en España y su impacto económico y social. Universidad Complutense Madrid, Neuroalianza.

28. Isaacs, B. J., Brown, I., Brown, R. I., Baum, N., Myerscough, T., Neikrug, S., Roth, N. D., Shearer, J., \& Wang, M. (2007). The international family quality of life project: Goals and description of a survey tool. Journal of Policy and Practice in Intellectual Disabilities, 4(3), 177-185. doi:10.1111/j.17411130.2007.00116.x

29. Longo- Araújo, E. \& Moreno-Valdés, M. T. (2007). Evaluación de la calidad de vida de los niños con distrofia muscular progresiva de Duchenne. Revista de Neurología, 45, 81-87.

30. Losada, A., Márquez, M., Vara-García, C., Gallego, L., Romero, R., \& Olazarán, J. (2017). Impacto psicológico de las demencias en las familias: propuesta de un modelo integrador. Revista Clínica Contemporánea, 8(e4), 1-27. doi:10.5093/cc2017a4

31. Madruga, M., Gozalo, M., Prieto, J., Adsuar, J. C., \& Gusi, N. (2020). Psychological symptomatology in informal caregivers of persons with dementia: Influences on health- related quality of life. International Journal of Environmental Research and Public Health, 17.

32. Manthorpe, J. \& Bowling, A. (2016). Quality of life measures for carers for people with dementia: Measurement issues, gaps in research and promising paths. Research, Policy and Planing, 31(3), 163-178.

33. Martínez-Martín, P., Rodríguez-Blázquez, C. \& Forjaz, M. J. (2012). Quality of Life and burden in caregivers for patients with Parkinson's disease: Concepts, assessment, and related factors. Expert Review of Pharmacoeconomics \& Outcomes Research, 12(2), 221-230. doi: 10.1586/ERP.11.106.

34. Mateo, I., Millán, A., García, M. M., Gutiérrez, P., Gonzalo, E., \& López, L. A. (2000). Family caregivers of people with neurodegenerative disease: Profile, contributions, and impact of care. Atención Primaria, 26(3), 139-144. doi:10.1016/s0212-6567(00)78630-6

35. Morgan, D., Kosteniuk, J., O'Connell, M. E., Kirk, A., Stewart, N. J., Seitz, D., Bayly, M., Chow, A. F., Elliot, V., Daku, J., Hack, T., Hoium, F., Kennett-Russill, D., \& Sauter, K. (2019). Barriers and facilitators to development and implementation of a rural primary health care intervention for dementia: A process evaluation. BMC Health Services Research, 19(1), 709. doi:10.1186/s12913-019-4548-5

36. Murray, J., Schneider, J., Banerjee, S., \& Mann, A. (1999). EUROCARE: A cross-national study of co-resident spouse carers for people with Alzheimer's disease: II- A qualitative analysis of the experience of caregiving. International Journal of Geriatrics Psychiatry, 14, 662-667.

37. Navarro-Abal, Y., López-López, M. J., Climent-Rodríguez, J. A., \& Gómez-Salgado, J. (2019). Burden, empathy, and resilience in dependent people caregivers. Gaceta Sanitaria, 33(3), 268-271. doi:10.1016/j.gaceta.2017.11.009

38. Nolan, M., Ryan, T., Eenderby, P., \& Reid, D. (2002). Towards a more inclusive vision of dementia care practice and research. Dementia: The International Journal of Social Research and Practice, 1(2), 193-211. doi:10.1177/147130120200100206

39. Oliveira, D. C., Vass, C., \& Aubeeluck, A. (2015). Ageing and quality of life in family carers of people with dementia being cared for at home: A literature review. Quality in Primary Care, 23(1), 18-30. 
40. Page, T. E., Farina, N., Brown, A., Daley, S., Bowling, A., Livingston, T. G., Knapp, M., Murray, J., \& Banerjee, S. (2017). Instruments measuring the diseasespecific quality of life of familiy carers of people with neurodegenerative diseases: A systematic review. BMJ Open, 7, e013611.

41. Park, J., Hoffman, L., Marquis, J., Turnbull, A. P., Poston, D., Mannan, H., Wang, M., \& Nelson, L. L. (2003). Toward assessing family outcomes of service delivery: Validation of a family quality of life survey. Journal of Intellectual Disability Research, 47 (parts 4/5), 367-384. doi: 10.1046/j.13652788.2003.00497.x

42. Pothiban, L., Srirat, C., Wongpakaran, N., \& Pankong, O. (2020). Quality of life and the associated factors among family caregivers of older people with dementia in Thailand. Nursing \& Health Sciences, 22(4), 913-920. doi:10.1111/nhs.12746

43. Riedel, B. C., Ducharme, J. K., \& Geldmacher, D. S. (2013). Family composition and expressions of family-focused care needs at an academic memory disorders clinic. International Journal of Alzheimer's Disease, 2013, 436271-436271. doi: 10.1155/2013/436271

44. Rillotta, F., Kirby, N., Shearer, J., \& Nettelbeck, T. (2012). Family quality of life of Australian families with a member with an intellectual-developmental disability. Journal of Intellectual Disability Research, 56(1), 71-86. doi: 10.1111/j.1365-2788.2011.01462.x

45. Rose, K. M. Williams, I. C., Anderson, J. G., \& Geldmacher, D. S. (2020). Development and Validation of the Family Quality of Life in Dementia Scale. The Gerontologist. Advance online publication. doi: 10.1093/geront/gnaa022

46. Samuel, P. S. \& DiZazzo-Miller, R. (2019). Family quality of life: Perspectives of family caregivers of people with dementia. Physical \& Occupational Therapy in Geriatrics, 37(2), 94-107. doi:10.1080/02703181.2019.1613467

47. Schmidt, J., Schmidt, M., \& Brown, I. (2016). Quality of life among families of children with intellectual disabilities: A Slovene study. Journal of Policy and Practice in Intellectual Disabilities, 14(1), 87-102. doi: 10.1111/jppi.12188

48. Schüz, B., Czerniawski, A., Davie, N., Miller, L., Quinn, M. G., King, C., Carr, A., J Elliot, K.-E., Robinson, A., \& Scott, J. L. (2015). Leisure time activities and mental health in informal dementia caregivers. Applied Psychology: Health and Well-Being, 7(2), 230-248. doi:10.1111/aphw.12046

49. Steel, R., Poppe, L., Vandevelde, S., Van Hove, G., \& Claes, C. (2011). Family quality of life in 25 Belgian families: Quantitative and qualitative exploration of social and professional support domains. Journal of Intellectual Disability Research, 55(12), 1123-1135. doi: 10.1111/j.1365-2788.2011.01433.x

50. Summers, J. A., Poston, D. J., Turnbull, A. P., Marquis, J., Hoffman, L., Mannan, H., \& Wang, M. (2005). Conceptualizing and measuring family quality of life. Journal of Intellectual Disability Research, 49(10), 777-783. doi:10.1111/j.1365-2788.2005.00751.x

51. Teitelman, J., Watts, J., Meisel, J., Woodward, J., \& McFarland-Smith, S. (2011). Alzheimer's caregiver focus groups: A method for identifying caregivers' perceptions of service coverage gaps. Gerontology \& Geriatrics Education, 22(1), 73-85.

52. Vellone, E., Piras, G., Venturini, G., Alvaro, R., \& Cohe, M. Z. (2012). Quality of life for caregivers of people with Alzheimer's disease living in Sardinia, Italy. Journal of Transcultural Nursing, 23(1), 46-55. doi: 10.1177/1043659611414199.

53. Veronese, S., Gallo, G., Valle, A., Cugno, C., Chio, A., Calvo, A., Rivoiro, C., \& Oliver, D. J. (2015). The palliative care needs of people severely affected by neurodegenerative disorders: A qualitative study. Progress in Palliative Care, 23(6), 331-342. doi: 10.1179/1743291X15Y.0000000007

54. World Health Organization, WHO (2019). Dementia. Key facts. Recovered from: https://www.who.int/en/news-room/fact-sheets/detail/dementia

55. Zuna, N., Summers, J. A., Turnbull, A. P., Hu, X., \& Xu, S. (2010). Theorizing about family, quality of life. In R. Kober (Ed.), Enhancing the quality of life of people with intellectual disabilities: From theory to practice (pp. 241-278). Springer.

\section{Tables}

Table 1

Family caregiver characteristics $(N=300)$ 


\begin{tabular}{|c|c|c|}
\hline Variable & $n$ & $\%$ \\
\hline \multicolumn{3}{|l|}{ Age $(M=62.48, S D=13.34$, Range $=25-88)$} \\
\hline Up to 65 years & 178 & 59.3 \\
\hline More than 65 years & 122 & 40.7 \\
\hline \multicolumn{3}{|l|}{ Gender } \\
\hline Male & 90 & 30.0 \\
\hline Female & 210 & 70.0 \\
\hline \multicolumn{3}{|l|}{ Educational level } \\
\hline No school certificate & 21 & 7.0 \\
\hline Elementary school & 150 & 50.0 \\
\hline High school & 68 & 22.8 \\
\hline University & 59 & 19.8 \\
\hline \multicolumn{3}{|l|}{ Employment status } \\
\hline Working (employees + self-employed) & 106 & 35.3 \\
\hline Not working (retired + unemployed + others) & 194 & 64.7 \\
\hline \multicolumn{3}{|l|}{ Income (EUR per month) } \\
\hline Up to 500 & 95 & 31.9 \\
\hline $500-1000$ & 102 & 34.2 \\
\hline $1000-1500$ & 69 & 23.1 \\
\hline More than 1500 & 32 & 10.7 \\
\hline \multicolumn{3}{|l|}{ Marital status } \\
\hline Married or with partner & 239 & 79.7 \\
\hline Others (divorced/separated, widowed, single) & 61 & 20.3 \\
\hline \multicolumn{3}{|l|}{ Place of residence - number of inhabitants } \\
\hline More than 10.000 & 61 & 20.3 \\
\hline $500-10.000$ & 107 & 35.7 \\
\hline Up to 500 & 132 & 44.0 \\
\hline \multicolumn{3}{|l|}{ Relationship with the person with dementia } \\
\hline Spouse or partner & 117 & 40.9 \\
\hline Son/Daughter & 148 & 51.7 \\
\hline Others & 21 & 7.3 \\
\hline \multicolumn{3}{|l|}{ Primary caregiver } \\
\hline Yes & 280 & 93.3 \\
\hline No & 20 & 6.7 \\
\hline \multicolumn{3}{|l|}{ Living condition } \\
\hline Living with the patient & 225 & 75.0 \\
\hline Not living with the patient & 75 & 25.0 \\
\hline
\end{tabular}

Table 2

Care-recipient characteristics $(N=300)$ 


\begin{tabular}{|c|c|c|}
\hline Variable & $n$ & $\%$ \\
\hline \multicolumn{3}{|l|}{ Age $(M=79.3, S D=11.7$, Range $=20-98)$} \\
\hline Gender & 120 & 40.0 \\
\hline Male & 180 & 60.0 \\
\hline \multicolumn{3}{|l|}{ Female } \\
\hline \multicolumn{3}{|l|}{ Diagnosis } \\
\hline Dementia & 163 & 54.3 \\
\hline Parkinson's Disease & 80 & 26.7 \\
\hline Multiple Sclerosis & 20 & 6.7 \\
\hline Others (unknown by family; several NDs) & 37 & 12.3 \\
\hline \multicolumn{3}{|l|}{ Dependence } \\
\hline Yes & 202 & 67.3 \\
\hline No & 98 & 32.7 \\
\hline \multicolumn{3}{|l|}{ Degree of dependence } \\
\hline Degree 1 & 46 & 23.1 \\
\hline Degree 2 & 61 & 30.7 \\
\hline Degree 3 & 92 & 46.2 \\
\hline \multicolumn{3}{|l|}{ Supports needed } \\
\hline None & 27 & 9.0 \\
\hline Very few & 32 & 10.7 \\
\hline Some & 75 & 25.0 \\
\hline Quite a lot & 56 & 18.7 \\
\hline A lot & 110 & 36.7 \\
\hline \multicolumn{3}{|l|}{ Communication skills } \\
\hline Poor communication & 76 & 25.3 \\
\hline Only basic needs & 26 & 8.7 \\
\hline Needs, desires, ideas & 42 & 14.0 \\
\hline Coherent on some topic & 66 & 22.0 \\
\hline Coherent on many topics & 90 & 30.0 \\
\hline
\end{tabular}

Table 3

Descriptive Statistics for Caregivers and Care Recipients in focus groups 


\begin{tabular}{|lll|}
\hline Caregivers' sociodemographic data $(\mathbf{N = 2 1})$ & $\mathbf{N = 1 0}$ & $\mathbf{N = 1 1}$ \\
& Dementia & Parkinson \\
\hline Caregiver's age in years & \\
Age (Range = 40-79) & \\
\hline Caregiver's gender & & \\
Female & 7 & 10 \\
Male & 3 & 1 \\
\hline Caregiver's role & & \\
Primary Caregiver & 7 & 9 \\
Shared Primary Caregiver & 3 & 2 \\
\hline Caregiver's relationship & & \\
Spouse & 6 & 9 \\
Sibling & 1 & 1 \\
Son/daughter & 3 & 0 \\
Daughter-in-law & 0 & 1 \\
\hline Care recipient's sociodemographic data $(\boldsymbol{N = 2 1 )}$ & & \\
\hline Care recipient's age in years $(\geq 70$ years $)$ & & \\
\hline Care recipient's gender & & \\
Female & & \\
Male & & \\
\hline
\end{tabular}

Table 4

Descriptive results of the FQOLS-ND

\begin{tabular}{|lllllll|}
\hline & \multicolumn{3}{l}{ Dimensions } & \multicolumn{3}{ll}{ Satisfaction } \\
\hline \multirow{2}{*}{ Attainment } & \multicolumn{4}{l|}{} \\
\cline { 2 - 7 } & Mean & Median & SD & Mean & Median & SD \\
\hline Family health & 3.64 & 4.00 & 0.69 & 3.66 & 4.00 & 0.84 \\
\hline Financial well-being & 3.53 & 4.00 & 0.64 & 3.58 & 4.00 & 0.69 \\
\hline Family relationships & 4.41 & 5.00 & 0.72 & 4.35 & 5.00 & 0.80 \\
\hline Support from others & 3.09 & 3.00 & 1.26 & 3.72 & 4.00 & 0.94 \\
\hline Support from services & 2.83 & 3.00 & 1.02 & 3.11 & 3.00 & 1.11 \\
\hline Influence of values & 3.49 & 3.00 & 0.86 & 3.64 & 4.00 & 0.82 \\
\hline Careers and planning for careers & 3.96 & 4.00 & 0.71 & 3.98 & 4.00 & 0.75 \\
\hline Leisure and recreation & 3.25 & 3.00 & 0.98 & 3.43 & 4.00 & 0.95 \\
\hline Community interaction & 3.74 & 4.00 & 0.80 & 3.83 & 4.00 & 0.71 \\
\hline Global family quality of life & 3.52 & 3.50 & 0.49 & 3.71 & 3.80 & 0.49 \\
\hline General family quality of life & 3.65 & 4.00 & 0.70 & 3.69 & 4.00 & 0.47 \\
\hline
\end{tabular}

Table 5

Distribution of frequency of scores in satisfaction and attainment for the nine domains of the FQOL-ND 


\begin{tabular}{|c|c|c|c|c|c|c|c|c|c|c|}
\hline \multirow[t]{2}{*}{ Domains } & \multicolumn{5}{|c|}{ Attainment } & \multicolumn{5}{|l|}{ Satisfaction } \\
\hline & None & $\begin{array}{l}\text { Very } \\
\text { little }\end{array}$ & Some & $\begin{array}{l}\text { Quite a } \\
\text { lot }\end{array}$ & A lot & $\begin{array}{l}\text { Very } \\
\text { dissatisfied }\end{array}$ & Dissatisfied & $\begin{array}{l}\text { Neither satisfied nor } \\
\text { dissatisfied }\end{array}$ & Satisfied & $\begin{array}{l}\text { Very } \\
\text { satisfied }\end{array}$ \\
\hline Family health & $0 \%$ & $6 \%$ & $29.7 \%$ & $58.3 \%$ & $6 \%$ & $1 \%$ & $9.7 \%$ & $22.3 \%$ & $56 \%$ & $11 \%$ \\
\hline Financial well-being & $0.7 \%$ & $4.3 \%$ & $37.7 \%$ & $56 \%$ & $1.3 \%$ & $1 \%$ & $6.3 \%$ & $28 \%$ & $62.7 \%$ & $2 \%$ \\
\hline Family relationships & $0.3 \%$ & $0.7 \%$ & $9.3 \%$ & $36.7 \%$ & $53 \%$ & $0.7 \%$ & $2.7 \%$ & $8.7 \%$ & $37.3 \%$ & $50.7 \%$ \\
\hline Support from others & $14 \%$ & $13.6 \%$ & $30.3 \%$ & $33.7 \%$ & $8.3 \%$ & $1.3 \%$ & $7.4 \%$ & $30.3 \%$ & $42.3 \%$ & $18.7 \%$ \\
\hline Support from services & $13.7 \%$ & $19 \%$ & $40.7 \%$ & $24.3 \%$ & $2.3 \%$ & $12.7 \%$ & $13.7 \%$ & $28.7 \%$ & $40 \%$ & $5 \%$ \\
\hline Influence of values & $2.7 \%$ & $3.7 \%$ & $48.3 \%$ & $32.3 \%$ & $13 \%$ & $1.7 \%$ & $2.3 \%$ & $41 \%$ & $40 \%$ & $15 \%$ \\
\hline $\begin{array}{l}\text { Careers and planning for } \\
\text { careers }\end{array}$ & $0.3 \%$ & $3.3 \%$ & $15.7 \%$ & $61.7 \%$ & $19 \%$ & $1 \%$ & $4 \%$ & $11 \%$ & $64 \%$ & $20 \%$ \\
\hline Leisure and recreation & $6.7 \%$ & $14 \%$ & $31.7 \%$ & $43.3 \%$ & $4.3 \%$ & $5.3 \%$ & $10.7 \%$ & $25.3 \%$ & $52.7 \%$ & $6 \%$ \\
\hline Community interaction & $1.3 \%$ & $6.7 \%$ & $20 \%$ & $60.3 \%$ & $11.7 \%$ & $0.7 \%$ & $4 \%$ & $19 \%$ & $64.7 \%$ & $11.7 \%$ \\
\hline $\begin{array}{l}\text { Global family quality of } \\
\text { life }\end{array}$ & $0.7 \%$ & $5.7 \%$ & $26.7 \%$ & $62 \%$ & $5 \%$ & $1.3 \%$ & $7 \%$ & $18.7 \%$ & $67.3 \%$ & $5.7 \%$ \\
\hline
\end{tabular}

\section{Supplementary Files}

This is a list of supplementary files associated with this preprint. Click to download.

- Appendix1.docx

- Appendix2.docx 